\title{
Comparison of Antibiotic Resistance and Lipase Production in Extended Spectrum $\beta$-lactamases Producing and Non-producing Isolates of Pseudomonas aeruginosa
}

\author{
Alfia Alim, Aparna*, Antariksh Deep, Priyanka Yadav and Uma Chaudhary \\ Department of Microbiology, Pt. B D Sharma PGIMS, Rohtak, Haryana, India \\ *Corresponding author
}

\begin{tabular}{|c|c|}
\hline & A B S T R A C T \\
\hline & Pseudomonas aeruginosa is a major cause of nosocomial infections. Recently multidrug \\
\hline Keywords & $\begin{array}{l}\text { resistance and extended-spectrum } \beta \text {-lactamase (ESBL)-producing } P \text {. aeruginosa isolates } \\
\text { are emerging worldwide. These isolates are reported to be more virulent than the non- }\end{array}$ \\
\hline $\begin{array}{l}\text { Antibiotic } \\
\text { resistance }\end{array}$ & $\begin{array}{l}\text { multidrug resistance and non ESBL producing isolates. In order to find a correlation } \\
\text { between ESBL production and virulence, we tested one virulence factor involved in }\end{array}$ \\
\hline $\begin{array}{l}\text { Lipase, } \\
\text { Pseudomonas. }\end{array}$ & $\begin{array}{l}\text { pathogenicity- lipase production in ESBL and non ESBL producing isolates. A total of } 100 \\
\text { samples were evaluated. ESBL was determined phenotypically by CLSI method while }\end{array}$ \\
\hline Article Info & $\begin{array}{l}\text { lipase production was determined using egg yolk agar. Forty nine isolates produced ESBL } \\
\text { out of which } 47(95 \%) \text { were positive for lipase while } 51 \text { isolates were non-ESBL }\end{array}$ \\
\hline $\begin{array}{l}\text { Accepted: } \\
\text { 20 February } 2017 \\
\text { Available Online: } \\
10 \text { March } 2017\end{array}$ & $\begin{array}{l}\text { producing out of which } 34(67 \%) \text { were positive for lipase ( } \mathrm{p} \text { value }<0.05) \text {. Antibiotic } \\
\text { resistance was also found more in ESBL producers compared to non-ESBL producers. Our } \\
\text { data demonstrate that lipase production was higher in the ESBL producing isolates }\end{array}$ \\
\hline & 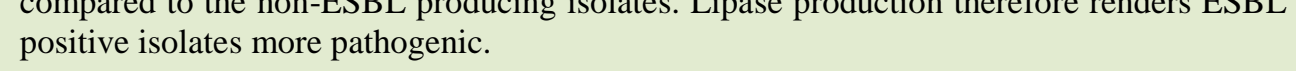 \\
\hline
\end{tabular}

\section{Introduction}

$P$. aeruginosa is one of the most important pathogenic bacteria which cause clinical infection as a result of its high resistance to antimicrobial agents and is therefore a particularly dangerous and dreaded bug.${ }^{[1]}$ Infections cause by $P$. aeruginosa often are difficult to treat due to high level of resistance to multiple antibiotics as a result of both intrinsic genes and acquisition of resistance genes. $^{[2]}$ In addition to the constitutive low susceptibility of $P$. aeruginosa to antimicrobial agents, emergence of new resistance mechanisms such as extendedspectrum ß-lactamase (ESBL) belonging to different classes have been identified in these organisms and therefore pose critical challenges to the health care giver. ${ }^{[2]}$

ESBLs are acquired plasmid-mediated $\beta$ lactamases and have the ability to inactivate $\beta$-lactams antibiotics containing an oxyiminogroup such as oxyimino-cephalosporins (e.g, ceftazidime, ceftriaxone, cefotaxime) as well as oxyimino-monobactam (e.g. aztreonam). They are not active against cephamycins and carbapenems. Generally, ESBLs are inhibited by $\beta$-lactamase-inhibitors such as clavulanate and tazobactam. ${ }^{[3]}$ Infection caused by ESBLproducers are associated with increased virulence of these strainsand severe adverse 
outcomes. This is often due to delay in effective therapy and the failure to use antibiotic active against ESBL-producing isolates. ${ }^{[2]}$

Pathogenesis of $P$. aeruginosa is multifactorial, involving several virulence factors that include structural components, toxins, and enzymes. ${ }^{[4]}$ Extracellular enzymes may cause hemorrhage in internal organs in systemic disease, alter host cellular receptors, and alter microbial behaviour by promoting invasiveness, serum resistance, and evasion of host immune mechanisms. ${ }^{[5]}$ Bacterial lipases are mostly extracellular and the major factor for the expression of lipase activity in Pseudomonas has always been carbon, since lipases are inducible enzymesand are thus generally produced in the presence of a lipid source such as oil or any other inducer, such as triacylglycerols, fatty acids. ${ }^{[6],[7]}$ Most published experimental data have shown that lipid carbon sources (especially natural oils) stimulate lipase production, and peptone is one of the most suitable substrate for maximum lipase production by $P$. aeruginosa ${ }^{[7]}$ Lipase production is known for their role in disease production and establishment of infection. ${ }^{[5]}$ Hence, this study was performed to evaluate and compare lipase production involved in pathogenicity in ESBL and nonESBL producing clinical isolates of $P$. aeruginosa.

\section{Material and Methods}

A total of 100 isolates of $P$. aeruginosa from various clinical specimens like urine, pus, blood, body fluids and sputum, were collected from both indoor and outdoor patients, irrespective of age and sex, and identified by standard microbiological procedures. ${ }^{[8]}$ The isolateswere subjectedto antimicrobial susceptibility testing performed by KirbyBauer disc diffusion method using Clinical and Laboratory Standard Institute (CLSI) criteria. Mueller-Hinton Agar (MHA) was used for antibiotic sensitivity testing. Various antibiotics were put up and plates incubated at $37^{\circ} \mathrm{C}$ for 24 hours.

Isolates showing reduced susceptibility to third generation cephalosporins were tested for ESBL production as per CLSI method. The test organism was inoculated on MHA plate. One $30 \mu \mathrm{g}$ disc of ceftazidime and one $30 \mu \mathrm{g}$ disc of cefotaxime and another $30 / 10 \mu \mathrm{g}$ disc of ceftazidime/clavulanic acid and $30 / 10 \mu \mathrm{g}$ disc of cefotaxime/clavulanic acid were placed on surface of agar plate. The plates were incubated at $35^{\circ} \mathrm{C}$ for $16-18$ hours. $A \geq 5 \mathrm{~mm}$ increase in zone diameter for the antimicrobial agent tested in combination with clavulanic acid versus its zone when tested alone was considered positive for ESBL production. ${ }^{[9]}$

For lipase production, the isolates were inoculated on egg yolk agar plates and the presence of pearly white iridescent sheen on the surface of the colonies after incubation at $37^{0} \mathrm{C}$ for 5 days, was taken as positive indicator for lipase production(Figure 1). ${ }^{[10]}$

\section{Results and Discussion}

Out of a total of 100 clinical isolates, maximum number of $P$. aeruginosa isolates were from urine $(49 \%)$, followed by pus $(20 \%)$, blood (19\%), sputum $(11 \%)$ and other body fluids ( $1 \%)$ samples.The antibiotic resistance pattern is depicted in Figure 2.

Among $\beta$-lactams group, the isolates of $P$. aeruginosa showed maximum resistance to ticarcillin /clavulanic acid (79\%) followed by aztreonam (78\%), ceftazidime (73\%), cefoxitin (68\%), ceftizoxime $(50 \%)$, ceftriaxone (48\%), cefepime (45\%), meropenem (34\%) and imipenem (33\%), while resistance to piperacillin/ tazobactam was seen only in $12 \%$ isolates. Among 
aminoglycosides group, the isolates of $P$. aeruginosa showed maximum resistance to netilmicin (64\%) followed by amikacin (43\%) and gentamicin (41\%). Among fluoroquinolones group, isolates of $P$. aeruginosa showed maximum resistance to norfloxacin $(67.3 \%)$ followed by ciprofloxacin (44\%). Among others group, resistance to colistin and polymyxin B was seen in $3 \%$ and $2 \%$ strains respectively.

Out of these 100 isolates, 58 were multi drug resistant(MDR; isolates showing resistance to at least three of the four antimicrobial drugs i.e $\beta$ - lactams, carbapenems, aminoglycosides, fluoroquinolones) and 20 were extreme drug resistant (XDR; isolates showing resistance to all the above mentioned four antimicrobial drugs). Forty nine (49\%) isolates were ESBL producers, while $51(51 \%)$ isolates were nonESBL producers(Figure 3).

On comparing the antibiotic resistance among ESBL producing and non-ESBL producing $P$. aeruginosa isolates, a significant statistical difference ( $p$ value $<0.05$ ) was observed for all cephalosporins except cefoxitin, carbepenems, aminoglycosides and ciprofloxacin (Table 1).

Eighty one $(81 \%)$ isolates were positive for lipase production out of which maximum was found in blood and other body fluids (100\%), followed by pus (85\%), sputum ( $82 \%)$ and urine $(71 \%)$. Out of the total lipase positive isolates, 47 were ESBL producers and 34 were non-ESBL producers (Figure 4).

The rate of isolation of $P$. aeruginosa from various clinical samples taken in our study was similar with Pitout et al. who had also reported maximum rate of isolation of $P$. aeruginosa isolates in urine (43\%), followed by pus (21\%) sputum (20\%) and blood (7\%) samples. ${ }^{[11]}$ Khan et al reported maximum rate of isolation of $P$. aeruginosa from pus
$(57.64 \%)$ followed by urine (24.2\%) samples. ${ }^{[12]}$ The difference in rates of isolation may be due to difference in type of samples received in different laboratories.

Studies done by various authors have reported the prevalence $84.5 \%$ and $68.75 \%$ multidrug resistant $P$. aeruginosa isolates. ${ }^{[13],[14]}$ In contrast, Tam et al. reported 14\% of MDR isolates. ${ }^{[14]}$ Delays in starting appropriate therapy may contribute to increased length of hospital stay and persistence of multidrug resistant $P$. aeruginosa isolates infection. ${ }^{[15],[16]}$

ESBL producing strains are usually found in those areas of hospitals where antibiotic use is frequent and the patient's condition is critical. ${ }^{[17]}$ In India, prevalence rate of ESBLs ranging from $28 \%$ to $84 \%$ has been reported from various parts of the country: Bakshi et al reported high prevalence $(50 \%)$ of ESBL production among $P$. aeruginosa at Patiala (Punjab) ${ }^{[18]}$ Similar incidence of ESBL production among $P$. aeruginosa (42.31\%) has been reported by researchers at AIIMS, New Delhi ${ }^{[19]}$ and from Coimbatore $(40 \%){ }^{[13]}$ Our study corroborates these findings. This relatively high rate of ESBL production in our study may be due to selection pressure caused by extensive use of $\beta$-lactam antibiotics in our hospital. This ESBL production rate might be much higher but could not be detected due to presence of silent genes which do not express phenotypically because in the present study we have not confirmed the ESBL genes using genotypic methods. ${ }^{[20]}$ High antibiotic resistance in ESBL producing $P$. aeruginosa isolates have also been reported by authors. ${ }^{[15]}$ Tavajjohi et al reported that resistant to antibiotics like piperacillin, cefotaxime, ceftriaxone, ceftazidime, imipenem, aztreonam was observed in $42.9 \%, 71.4 \%$, $57.1 \%, \quad 57.1 \%, \quad 28.5 \%, \quad 42.9 \%$ ESBL producing $P$. aeruginosa isolates, however no comparison in antibiotic resistance among 
ESBL and non ESBL producers has been done by these authors. ${ }^{[15]}$ In the present study, a significant statistical difference ( $p$ value $<0.05)$ was observed for resistance to aminoglycosides and fluoroquinolones in ESBL and non ESBL producing $P$. aeruginosa isolates. High antibiotic resistance to these antibiotics in ESBL producing $P$. aeruginosa isolates have been reported by other authors. Tavajjohi et al reported that resistance to antibiotics like gentamicin and ciprofloxacin was observed in $42.9 \%$ and 17.4\% ESBL producing $P$. aeruginosa isolates, respectively. ${ }^{[15]}$ Peshattiwar et al reported that, among $126 P$. aeruginosa isolates, $28(22 \%)$ were ESBL producers and total of sixty seven strains showed resistance to ceftazidime, of which $28(41.79 \%)$ were found in ESBL producers. ${ }^{[21]}$

Table.1 Comparison of antimicrobial resistance pattern of ESBL producing and non-ESBL producing $P$. aeruginosa isolate to various antibiotics

\begin{tabular}{|c|c|c|c|c|c|}
\hline \multirow{2}{*}{$\begin{array}{l}\text { Antimicrobial } \\
\text { drugs }\end{array}$} & \multicolumn{2}{|c|}{ ESBL producers $(n=49)$} & \multicolumn{2}{|c|}{ Non-ESBL producers $(\mathrm{n}=51)$} & \multirow[t]{2}{*}{ p value } \\
\hline & $\mathrm{n}$ & $\%$ & $\mathrm{n}$ & $\%$ & \\
\hline \multicolumn{6}{|l|}{$\beta$ - lactams } \\
\hline Ceftazidime & 49 & 100 & 24 & 47.1 & $<0.05$ \\
\hline Ceftizoxime & 45 & 91.8 & 5 & 9.8 & $<0.05$ \\
\hline Ceftriaxone & 47 & 95.9 & 1 & 2 & $<0.05$ \\
\hline Cefepime & 32 & 65.3 & 13 & 35.5 & $<0.05$ \\
\hline Cefoxitin & 36 & 73.5 & 32 & 62.7 & $>0.05$ \\
\hline Aztreonam & 42 & 85.72 & 36 & 70.6 & $>0.05$ \\
\hline Imipenem & 23 & 47 & 10 & 19.6 & $<0.05$ \\
\hline Meropenem & 24 & 49 & 10 & 19.6 & $<0.05$ \\
\hline $\begin{array}{l}\text { Piperacillin } \\
\text { /tazobactam }\end{array}$ & 9 & 18.4 & 3 & 5.8 & $>0.05$ \\
\hline $\begin{array}{l}\text { Ticarcillin/ } \\
\text { clavulanic acid }\end{array}$ & 40 & 81.6 & 39 & 76.5 & $>0.05$ \\
\hline \multicolumn{6}{|c|}{ Aminoglycosides } \\
\hline Gentamicin & 27 & 55 & 14 & 27.4 & $<0.05$ \\
\hline Amikacin & 29 & 59.2 & 14 & 27.4 & $<0.05$ \\
\hline Netilmicin & 37 & 75.5 & 27 & 53 & $<0.05$ \\
\hline \multicolumn{6}{|c|}{ Fluoroquinolones } \\
\hline Ciprofloxacin & 28 & 57 & 16 & 31.4 & $<0.05$ \\
\hline Norfloxacin & 16 & 32.7 & 17 & 33.3 & $>0.05$ \\
\hline \multicolumn{6}{|l|}{ Others } \\
\hline Polymyxin & 0 & 0 & 2 & 3.9 & $>0.05$ \\
\hline Colistin & 1 & 2 & 2 & 3.9 & $>0.05$ \\
\hline
\end{tabular}


Fig.1 Lipase production in egg yolk agar seen as a pearly white sheen on the surface of colony

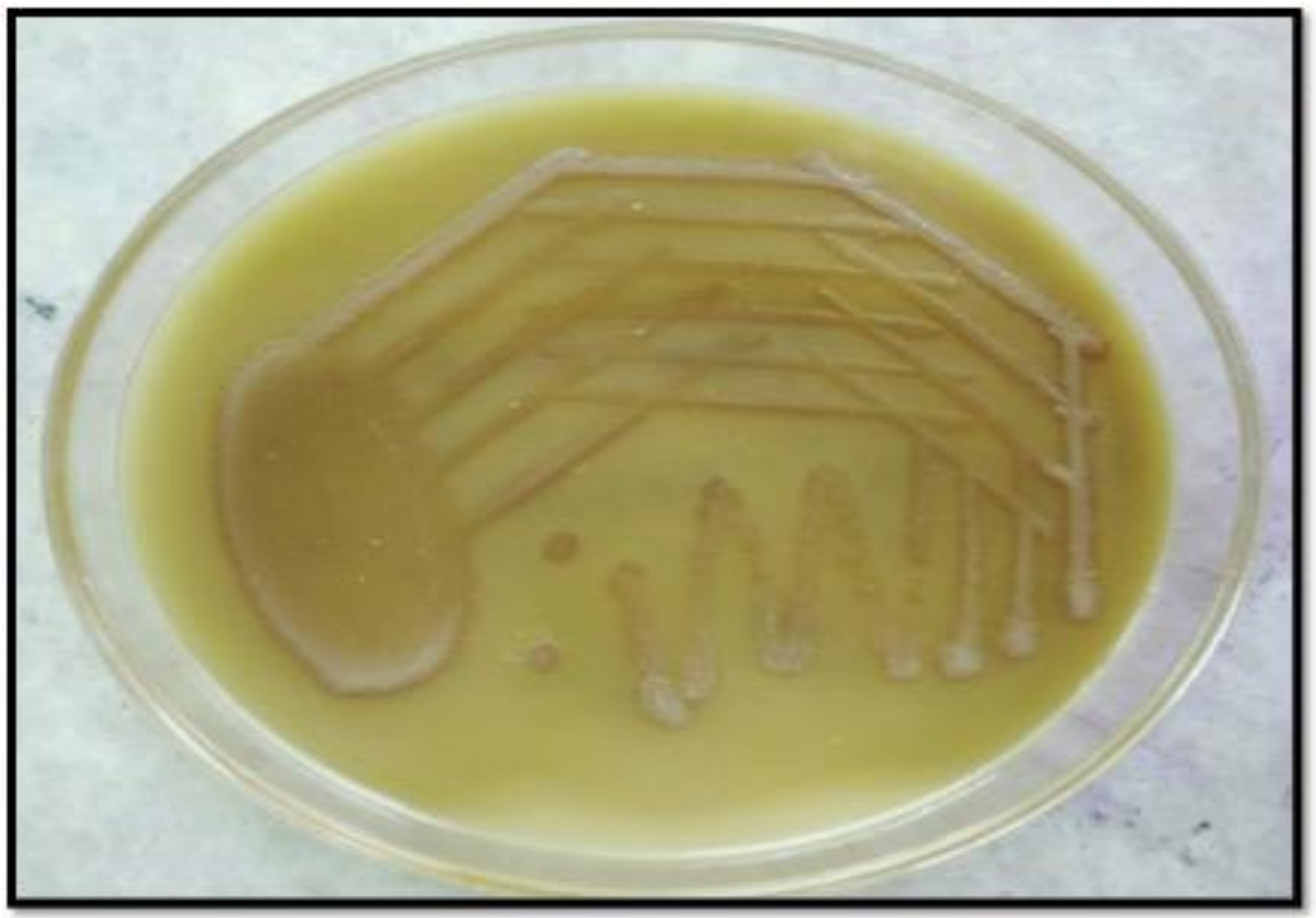

Fig.2 Antimicrobial resistance pattern of the 100 isolates of $P$. aeruginosa

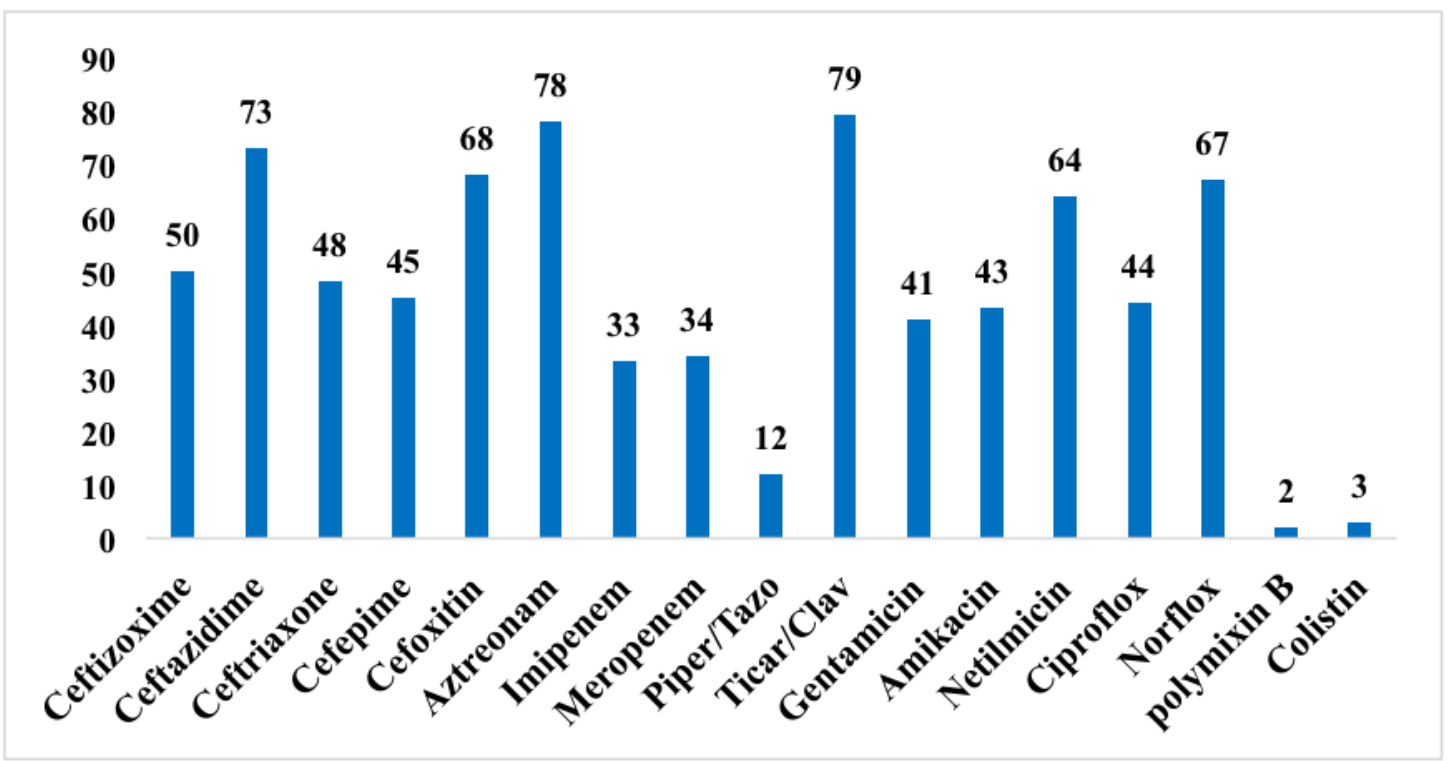


Fig.3 Distribution of ESBL and non-ESBL producing $P$. aeruginosa isolates

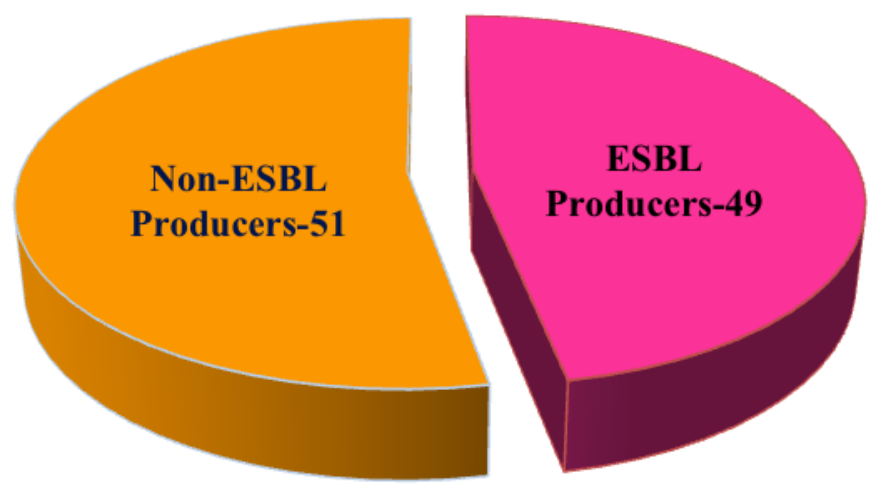

Fig.4 Lipase producing isolates in ESBL producers and non-producers

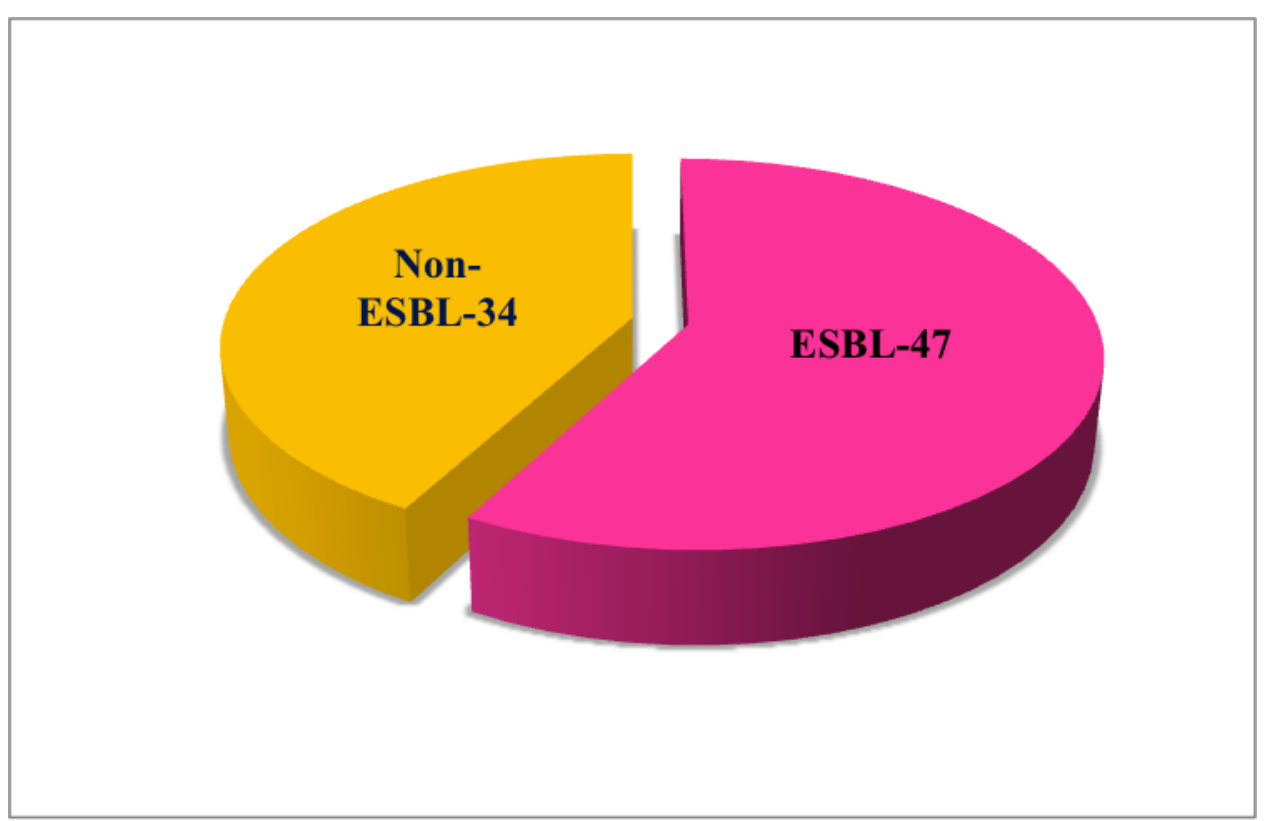

However, no comparision in antibiotic resistance pattern was made between ESBL producing and non-ESBL producing isolates.A decreased susceptibility of $P$. aeruginosa to the commonly used antibiotics has already been noted byprevious researchers. ${ }^{[22]}$ In this study, the ESBL producing isolates were significantly more resistance to anti-bacterial agents compared with non-ESBL producing isolates $(\mathrm{p}<0.05)$. The same results were reported for clinical isolates of enteric bacteria by Mansouri et al and the gram negative bacteria from urinary tract infections by Selvakumar et al and Mashouf et al. ${ }^{[23],[24]}$ This can be explained by the fact that ESBL producing bacteria usually 
have mobile genetic elements coding gene for resistance to other antibacterial agents. Different efflux pumps in $P$. aeruginosa are able to eject multiple antimicrobials from cell, including beta-lactams and effect penicillin as well as non-beta-lactams drugs such as fluoroquinolones and aminoglycosides. ${ }^{[25]}$

Lipase production in our study was high (81\%), more in ESBL producers than nonproducers which is similar to study done by Georgescu et alwhere lipase production was seen in $77 \%$ of $P$. aeruginosa. ${ }^{[26]}$ In another study by Mohammad on $P$. aeruginosa isolated from burn patients, $100 \%$ were positive for lipase production. ${ }^{[27]}$ In a study done by Maroui et al on virulence profiles of clinical and environmental $P$. aeruginosa isolates, lipase was produced in all the 68 $(100 \%)$ clinical strains. ${ }^{[28]}$ In a similar study done by Khalil et al, the amount of lipase production was $81 \%$ and the incidence was more in ESBL producers than non-ESBL producers. ${ }^{[29]}$ In a study done by Finlayson and Brown comparing the antibiotic resistance and virulence factors in pigmented and non-pigmented $P$. aeruginosa, the incidence of lipase production in pigmented and non-pigment isolates was $82.5 \%$ and 17.5 $\%$ respectively. However the total lipase production in 57 isolates taken in the study was $72 \%$. ${ }^{[30]}$

In conclusion, ES $\beta$ L-producing $P$. aeruginosa clinical isolates are armed with a large arsenal of virulence factors. Lipase production in these pathogens enable themto breach the human innate immune system, to infect host cells, and to modulate human adaptive immune mechanisms, serving the goal of establishing systemic or more localized chronic colonization and hence associated with increase virulence. The obtained results clearly indicate the importance of the recommendation that the antibiotic resistance as well as virulence factors of $P$. aeruginosa must be periodically studied in order to understand the possible co-regulatory mechanisms that might be involved in their expression.

\section{References}

1. Upadhyay $\mathrm{S}$, RanjanSen $\mathrm{M}$, Bhattacharjee A. Presence of different beta-lactamase classes among clinical isolates of Pseudomonas aeruginosa expressing AmpC beta-lactamase enzyme. J Infect DevCtries 2010;4:23942

2. Mansouri S, Norouzi F, Moradi M, Nakhaee N. Comparison of virulence factors among clinical isolates of Pseudomonas aeruginosa producing and non-producing extended spectrum $\beta$ lactamases. Curr Res Bacteriol. 2011; 4:85-93

3. Damron FH, Goldberg JB. Proteolytic regulation of alginate overproduction in Pseudomonas aeruginosa.Mol.Microbiol. 2012;84(2):595-607

4. Murray PR, Rosenthal K, Kobayashi GS, Pfaller MA. Medical Microbiology.6th ed.USA:Mosby; 1998

5. Casadevall A, Pirofski L. Virulence factors and their mechanisms of action. Water Health J 2009;7:S1-S18

6. Lotti M, Monticelli S, Montesinos JL, Brocca S, Valero F, Lafuente J. Physiological control on the expression and secretion of Candida rugosalipase. ChemPhys Lipids 1998;93:143-8

7. Abdel-Fattah YR. Optimization of thermostable lipaseproduction from a thermophilicGeobacillus sp. using BoxBehnken experimental design. BiotechnolLett2002;24:1217-22

8. Collee JG, Mles RB, Watt B. Tests for identification of bacteria. In:Collee JG, Fraser AG, Marmon BP, Simmons A, editors. Mackie and McCartney Practical Medical Microbiology. $14^{\text {th }}$ ed. New 
York: Churchill Livingstone; 1996.p.13149

9. Elmer W Koneman, Stephen D Allen, William M Jendaet. al. Color Atlas and Textbook of Diagnostic Microbiology, 6th edition 2006. Publishers J.B. Lippincot Company.

10. Collee JG, Marr W. Specimen collection, culture containers and media. In:Collee JG, Fraser AG, Marmon BP, Simmons A, editors. Mackie and McCartney Practical Medical Microbiology, 14th ed. New York; Churchill Livingstone; 1996.p.95111

11. Pitout JDD, Gregson DB, Poirel L, MaClure JA, Le P, Church DL. Detection of Pseudomonas aeruginosaproducing MBLs in a large centralized laboratory. JClinMicrobiol 2005;43:3129-35

12. Khan JA, Igbal Z, Rahman SU, Farzana K, Khan A. Prevalence and resistance pattern of Pseudomonas aeruginosa against various antibiotics. Pak J Pharm Sci 2008;21:311-5

13. Lim KT, Yasin RM, Yeo CC, Puthucheary SD, Balan G, Maning N et al. Genetic fingerprinting and antimicrobial susceptibility profiles of Pseudomonas aeroginosahospital isolates in Malaysia. J MicrobiolImmunol Infect 2009;42:197-209

14. Mirsalehian A, Feizabadi M, Nakhjavani FA, Jabalameli F, Goli H, Kalantari N. Detection of VEB-1, OXA-10 and PER-1 genotypes in extended-spectrum beta lactamase-producing Pseudomonas aeruginosastrains isolated from burn patients. Burns 2010; 36:70-4

15. Tavajjohi Z, Moniri R, Khorshidi A. Detection and characterization of multidrug resistance and extendedspectrum-beta-lactamase-producing (ESBLS) Pseudomonas aeruginosa isolates in teaching hospital. Af $\mathrm{J}$ Microbiol Res. 2011;5(20):3223-8
16. Amutha R, Padmakrishnan, Murugan T, Devi MPR. Studies on multidrug resistant $P$. aeruginosa from pediatric population with special reference to extended spectrum beta lactamese. Indian $\mathbf{J}$ SciTechnol 2009;2:11-3.

17. Davies JC, Bilton D. Bugs biofilms, and resistance in cystic fibrosis. Respir Care 2009;54:628-38.

18. Bakshi R, Walia G, Shikha J. Prevalence of extended spectrum $\beta$-lactamases in multidrug resistant strains of gram negative Bacilli. J Acad Indus Res. 2013;1:558-60.

19. Goel V, Hogade SA, Karadesai SG. Prevalence of extended spectrum betalactamases, AmpC beta-lactamase, metallo-beta-lactamase producing Pseudomonas aeruginosa and Acinetobacterbaumannii in an intensive care unit in a tertiary care hospital. J SciSoc 2013; 40:28-31.

20. Jacoby GA. AmpC $\beta$ lactamases. ClinMicrobiol Rev 2009;22(1):161-82.

21. Peshattiwar PD, Peerapur BV. ESBL and MBL mediated resistance in Pseudomonas aeruginosa: an emerging threat to clinical therapeutics. J Clin Diagnostic Res 2011;5:1552-4.

22. Aggarwal R, Chaudhari U, Bala K. Detection of extended - spectrum Blactamases in Psuedomonasaeruginosa. Indian J PatholMicrobiol2008;51(2): $222-24$

23. Selvakumar BN, Jasmine R. Antibiotic susceptibility of ESBL-producing urinary isolates at a tertiary care hospital in Tiruchirappalli, South India. J. Med. Sci. 2007;7:443-6.

24. Yousefi-Mashouf R, Hashemi SH. The epidemiology of burn wound infections in patients hospitalized in burn wound infections in patients hospitalized in burn centre of Hamedan, Western Iran.J.Med.Sci. 2006;6: 426-31. 
25. Livermore DM, Woodford N. The betalactamase threat in Enterobacteriaceae, Pseudomonas and Acinetobacter. Trends Microbiol. 2006;14:413-20.

26. Georgescu M, Gheorghe I, Curutiu C, Lazar V, Bleotu C, Chifiriuc MC. Virulence and resistance features of Pseudomonas aeruginosa strains isolated from chronic leg ulcers. BMC Infectious Diseases 2016;16(1):92.

27. Mohammad HH. Phenotypic investigation for virulence factors of pyocine producing Pseudomonas aeruginosa isolated from burn wounds in Iraq. Int $\mathbf{J}$ Scien Research Publ.2013;4(7):42-4.

28. Maroui I, Aboulkacem A, Timinouni M, Belhaj A. Virulence profiles of clinical and environmental Pseudomonas aeruginosaisolates from Central Morocco. Afr. J. Microbiol. Res. 2016;10(14):473-80.

29. Khalil MA, Ibrahim Sonbol F, Mohamed AF, Ali SS. Comparative study of virulence factors among ES $\beta$ L-producing and non-producing Pseudomonas aeruginosaclinical isolates. Turk J Med Sci 2015;45(1): 60-9.

30. Finlayson EA, Brown PD. Comparison of antibiotic resistance and virulence factors in pigmented and non-pigmented Pseudomonas aerogenosa. West Indian Med J.2011;60(1):24-32.

\section{How to cite this article:}

Alfia Alim, Aparna, Antariksh Deep, Priyanka Yadav and Uma Chaudhary. 2017. Comparison of Antibiotic Resistance and Lipase Production in Extended Spectrum $\beta$-lactamases Producing and Non-producing Isolates of Pseudomonas aeruginosa. Int.J.Curr.Microbiol.App.Sci. 6(3): 2038-2046. doi: https://doi.org/10.20546/ijcmas.2017.603.232 